\title{
Dendritic and Postsynaptic Localizations of Glycine Receptor $\alpha$ Subunit mRNAs
}

\author{
Claudia Racca, Alejandra Gardiol, and Antoine Triller \\ Laboratoire de Biologie Cellulaire de la Synapse, INSERM, CJF 94-10, Ecole Normale Supérieure, 75005 Paris, France
}

Some synaptic neurotransmitter receptors, such as those for glycine, have somato-dendritic distributions. Although the machinery for protein synthesis and several mRNAs are present in dendrites and close to synapses in central neurons, so far the mRNAs for neurotransmitter receptors have not been found unequivocally in dendrites. The glycine receptor (GlyR), a ligand-gated channel mediating a chloride-dependent inhibition, is composed of transmembrane $\alpha$ and $\beta$ subunits. GlyRs are only present at glycinergic postsynaptic differentiation, where they are stabilized by the associated protein gephyrin. With light nonradioactive in situ hybridization (ISH), we observe that GlyR $\alpha$ subunit mRNAs are present in both somata and dendrites of most neurons of the ventral horn of rat spinal cord, whereas the $\beta$ subunit and gephyrin mRNAs are predominantly in somata. Interestingly, within dendrites GlyR $\alpha$ subunit mRNAs form aggregates that are mostly localized peripherally to the dendritic axial core. Electron microscopic ISH shows that GlyR $\alpha$ subunit mRNAs are associated with postsynaptic differentiations. At these sites, the GlyR $\alpha$ subunit mRNAs are detected in close association with subsynaptic cisternae. This targeting of $\alpha$ subunit mRNAs to postsynaptic domains could provide a means of dynamically modulating synaptic efficacy by changing the composition and the density of receptors at glycinergic synapses.

Key words: glycine receptor; dendritic mRNA; spinal cord; in situ hybridization; immunocytochemistry; confocal microscopy; electron microscopy
Different types of neurotransmitter receptors and ion channels segregate in discrete domains at different locations of the neuronal plasmalemma. This mosaic organization of the membrane determines the interactions between the various inputs and their effects on the activity of the neuron. Targeting molecules to particular cytoplasmic domains is one mechanism of the spatial and temporal regulation of gene expression. Proteins are generally sorted according to particular peptide signals that target proteins to particular cellular sites (Rindler et al., 1984; Dotti and Simons, 1990; Pelhalm and Munro, 1993). mRNAs have also been found to be differently distributed within the cytoplasm of various cells. The location of mRNA might be a means of targeting and confining their corresponding protein to particular cytoplasmic compartments. Examples of localized mRNAs have been described in various species (Drosophila, Xenopus, chicken, and rat) and cell types (oocytes, fibroblasts, neurons, muscle cells, and oligodendrocytes). The products encoded by these mRNAs have been proposed to participate in establishing and/or maintaining the cell polarity or in fulfilling spatially restricted functions (for review, see Steward, 1995; St Johnston, 1995). Various mRNAs have been shown to be localized both in the soma and in the dendrites of neurons (Steward, 1995; St Johnston, 1995). The presence of mRNAs together with the protein synthetic machinery in

Received Oct. 1, 1996; revised Dec. 16, 1996; accepted Dec. 18, 1996.

This work was supported by a grant from Institut de Recherche sur la Moelle Epinière. C.R. was supported by Institut National de la Santé et de la Recherche Médicale, and A.G. was supported by a French Government fellowship. We thank Drs. B. Barbour, M. Häusser, J. Kupper, R. Miles, A. Trembleau, and C. Vannier for their comments, suggestions, and for critically reading this manuscript. Help with electron microscopy from P. Rostaing is greatly appreciated. We also acknowledge Dr. H. Betz for supplying anti-GlyR monoclonal antibody 4a.

Correspondence should be addressed to Antoine Triller, Laboratoire de Biologie Cellulaire de la Synapse, INSERM, CJF 94-10, Ecole Normale Supérieure, 46 Rue d'Ulm, F-75005 Paris, France.

Copyright (C) 1997 Society for Neuroscience $\quad 0270-6474 / 97 / 171691-10 \$ 05.00 / 0$ dendrites at or near postsynaptic sites (Steward and Levy, 1982; Steward, 1983; Steward and Fass, 1983; Steward and Reeves, 1988; Peters et al., 1991) may allow local and rapid synthesis of key synaptic proteins (Steward and Falk, 1985; Torre and Steward, 1992; Thomas et al., 1994; Link et al., 1995; Lyford et al., 1995).

In ventral horn neurons of rat spinal cord, GlyRs are confined to the postsynaptic membrane and concentrated at the level of synaptic complexes (Triller et al., 1985, 1987; Altschuler et al., 1986; Seitanidou et al., 1988). This ligand-gated ion channel is a heteromeric complex (Langosch et al., 1988) composed of two subunits, $\alpha$ and $\beta$, and the associated cytoplasmic protein gephyrin (Kuhse et al., 1995). Gephyrin is a peripheral protein involved in clustering GlyRs in microdomains at the postsynaptic membrane (Kirsch et al., 1993b), probably by linking them to the underlying cytoskeleton (Kirsch et al., 1991; Kirsch and Betz, 1995).

In our study, we investigated the subcellular distribution of the mRNAs for the constituents of the GlyR complex. We used nonradioactive in situ hybridization techniques and applied them to ventral horn neurons of adult rat spinal cord. We show (1) a different localization of the different GlyR complex mRNAs: GlyR $\alpha 1$ and $\alpha 2$ subunit mRNAs are present within neuronal somata and dendrites, whereas GlyR $\beta$ subunit and gephyrin mRNAs seem confined to the somata; and (2) GlyR $\alpha$ subunit mRNAs often close to synapses and associated with subsynaptic cisternae. This dendritic and postsynaptic localization of GlyR $\alpha$ mRNAs may be used to rapidly alter the properties of individual glycinergic synapses.

This work has appeared in abstract form (Racca et al., 1996).

\section{MATERIALS AND METHODS}

Oligonucleotide probes. Oligonucleotide probes encoded the following: $\alpha 1$ residues 1050-1094 and 1096-1143 (Grenningloh et al., 1987; Malosio et al., 1991); $\alpha 2$ residues 1682-1726 and 1789-1810 (Kuhse et al., 1990; Malosio et al., 1991); $\beta$ residues 325-369 and 1476-1496 (Grenningloh et 
al., 1990; Malosio et al., 1991); and gephyrin residues 441-461 and 2076-2120 (Prior et al., 1992; Kirsch et al., 1993a).

Nonradioactive in situ hybridization. The regional distribution of GlyR complex mRNAs was studied previously by radioactive in situ hybridization (ISH) (Malosio et al., 1991; Sato et al., 1991; Kirsch et al., 1993a). However, because of their design, these experiments could not resolve the subcellular localization of the mRNAs. In contrast, nonradioactive ISH gives an unequivocal view of the subcellular distribution of the hybridization signal, allowing mRNAs to be localized by light and electron microscopic (EM) techniques.

Nonradioactive in situ hybridization: alkaline phosphatase and peroxidase enzymatic reactions. Adult Sprague Dawley rats (IffaCredo) were deeply anesthetized with pentobarbital (60 mg/kg body weight, i.p.) and intracardially perfused with $4 \%$ paraformaldehyde (PFA) in PBS $(0.1 \mathrm{M}, \mathrm{pH}$ 7.2). Spinal cords were removed and post-fixed in the same fixative overnight at $4^{\circ} \mathrm{C}$. Spinal cord $30 \mu \mathrm{m}$ sections were cut on a vibratome, collected in PBS, and permeabilized with $0.1 \%$ Triton X-100 in PBS. The free-floating sections were pretreated for $3 \mathrm{hr}$ at $42^{\circ} \mathrm{C}$ with prehybridization buffer ( $4 \times$ SSC, $1 \times$ Denhardt's solution, $10 \mu \mathrm{g} / \mathrm{ml}$ yeast tRNA) and then hybridized overnight at $42^{\circ} \mathrm{C}$ in hybridization buffer $(50 \%$ formamide, $600 \mathrm{mM} \mathrm{NaCl}, 80 \mathrm{~mm}$ Tris- $\mathrm{HCl}$, pH 7.5, $4 \mathrm{~mm}$ EDTA, $10 \mu \mathrm{g} / \mathrm{ml}$ yeast tRNA) containing $10 \mathrm{nM} 3^{\prime}$-end digoxigenin (DIG)-labeled oligonucleotides as described previously (Trembleau et al., 1994). The next day, sections were rinsed in $2 \times \mathrm{SSC}$ and $1 \times \mathrm{SSC}$ for $1 \mathrm{hr}$ each, and the high-stringency wash was in $0.1 \times \mathrm{SSC}$ at $42^{\circ} \mathrm{C}$ for $50 \mathrm{~min}$. DIG was revealed by one of the following. (1) Alkaline phosphatase-conjugated sheep anti-DIG Fab fragment (1:750, overnight, $4^{\circ} \mathrm{C}$; Boehringer Mannheim) in $100 \mathrm{~mm}$ Tris-HCl, pH 7.5, $150 \mathrm{~mm} \mathrm{NaCl}, 2 \%$ BSA, 0.3\% Triton $\mathrm{X}-100$ was used. The alkaline phosphatase reaction was developed with nitro blue tetrazolium chloride (NBT) and X-Phosphate (Boehringer Mannheim) in $100 \mathrm{~mm}$ Tris- $\mathrm{HCl}, \mathrm{pH} 9.5,100 \mathrm{~mm} \mathrm{NaCl}, 50 \mathrm{~mm} \mathrm{MgCl}$. Sections were rinsed three times in $100 \mathrm{~mm}$ Tris- $\mathrm{HCl}, \mathrm{pH} 7.4,150 \mathrm{~mm}$ $\mathrm{NaCl}$ between each of these incubations. (2) Sheep anti-DIG (1:1000, overnight at $4^{\circ} \mathrm{C}$; Boehringer Mannheim) in PBS-1\% BSA, followed by biotinylated donkey anti-sheep/goat $\operatorname{IgG}(1: 200,2 \mathrm{hr}$ at room temperature; Amersham) in PBS, and an ABC Elite kit (1 hr; Vector Laboratories) was used. The peroxidase reaction was revealed by incubating the sections in 3,3'-diaminobenzidine (DAB) and hydrogen peroxide (SigmaFast, Sigma). Three rinses for $10 \mathrm{~min}$ in PBS followed each of these incubations. Sections were then mounted on slides with Mowiol (Hoechst).

Fluorescent nonradioactive in situ hybridization and immunocytochemistry. ISH was as described above except for the visualization of the DIG Double immunolabelings for mRNAs and gephyrin or GlyR proteins were contemporaneously revealed by the following: sheep anti-DIG (1: 1000, overnight, $4^{\circ} \mathrm{C}$; Boehringer Mannheim) in $100 \mathrm{~mm}$ Tris- $\mathrm{HCl}, \mathrm{pH}$ 7.5, $150 \mathrm{~mm} \mathrm{NaCl}, 2 \% \mathrm{BSA}, 0.3 \%$ Triton X-100, and carboxymethyl indocyanine (Cy3)-donkey anti-sheep $\operatorname{IgG}(\mathrm{H}+\mathrm{L})$ antibody $(1: 400,2 \mathrm{hr}$ at room temperature; Jackson ImmunoResearch) in PBS/1\% BSA for ISH; anti-gephyrin mAb 7a (1:100; Boehringer Mannheim) (Pfeiffer et al., 1984) or anti-GlyR mAb 4a (1:100) (Pfeiffer et al., 1984) overnight at $4^{\circ} \mathrm{C}$ in $100 \mathrm{~mm}$ Tris- $\mathrm{HCl}$, pH 7.5, $150 \mathrm{mM} \mathrm{NaCl}, 2 \%$ BSA, $0.3 \%$ Triton X-100; followed by biotinylated rabbit anti-mouse $\operatorname{IgG}(1: 500,2 \mathrm{hr}$ at room temperature; Vector Laboratories) in PBS/1\% BSA and streptavidinfluorescein isothiocyanate (FITC; 1:200, $3 \mathrm{hr}$ at room temperature; Jackson ImmunoResearch) in PBS. Each incubation was followed by three washes in PBS (10 min each). Finally, sections were mounted on slides with Vectashield (Vector Laboratories) and observed with a Molecular Dynamics confocal laser scanning microscope equipped with appropriate filters for a simultaneous detection of FITC and Cy3 fluorochromes. The background noise was reduced by applying a Gaussian filter to the optical sections.

Electron microscopic nonradioactive in situ hybridization. Adult Sprague Dawley rats (IffaCredo) were anesthetized as above and perfused with $4 \%$ PFA and $0.1 \%$ glutaraldehyde in PBS. EM ISH was as described above except that the 50- $\mu \mathrm{m}$-thick vibratome sections were cryoprotected in $20 \%$ glycerol $/ 20 \%$ sucrose in PBS and permeabilized by freezing and thawing. The DIG-labeled probes were detected either by (1) peroxidaseDAB reaction (see above), or (2) a preembedding immunogold (rabbit nanogold anti-sheep IgG, 1:50; Nanoprobes)-silver enhancement-gold toning protocol as described by Trembleau et al. (1994). The sections were then osmicated and flat-embedded in araldite resin. Semithin and ultrathin sections were prepared and contrasted with uranyl acetate and lead citrate before examination under a Jeol CX-II transmission electron microscope.
Controls. Sense and random oligonucleotide probes and omission of any oligonucleotides or any single step in the development of alkaline phosphatase or DAB reactions, and fluorescence ISH, resulted in no labeling of any cells (data not shown). In our study, the oligonucleotide probes that we used were the same as those used by previous for radioactive ISH studies (Malosio et al., 1991; Sato et al., 1991; Kirsch et al., 1993a). Furthermore, to rule out the possibility of aspecificity of the probes, other oligonucleotides for each studied mRNA were tested. Similar distribution patterns and subcellular localizations were observed for each GlyR complex mRNA, independently of the corresponding probe used.

For double-fluorescence experiments, controls included either the independent omission of each single major step of the immunocytochemistry and/or ISH protocols, one at a time, or the replacement of the primary antibody by normal goat serum (Gibco).

\section{RESULTS \\ Dendritic localization of GlyR $\alpha$ subunit mRNAs}

The alkaline phosphatase-NBT (Fig. 1) or peroxidase-DAB (data not shown) color development of the hybridization signal revealed that the spatial distribution of GlyR complex mRNAs within the cell was dependent on the mRNA type. Hybridization signals for all GlyR complex mRNAs were observed in the perykarial cytoplasm and around but not in the nuclei of the cells (Fig. 1). In addition, neurites in the majority of neurons that showed cell body hybridization for GlyR $\alpha 1$ or $\alpha 2$ subunit mRNAs were also labeled (Fig. $1 A, B$, respectively). Even in cases in which the somata were only weakly labeled for GlyR $\alpha 1$ or $\alpha 2$ subunit mRNAs, the signal in the processes was detectable. Furthermore, many processes, cut in cross or tangential sections and not attached to their parent soma, were positive for GlyR $\alpha 1$ or $\alpha 2$ subunit mRNAs.

GlyR and gephyrin proteins have been found previously by immunostaining to be restricted to somata and dendrites in adult neurons (see references in Kuhse et al., 1995), where they form clusters at the cell surface outlining soma and dendrites. The GlyR-immunoreactive clusters have also been shown by EM studies on spinal cord to correspond to postsynaptic differentiations (Triller et al., 1985, 1987; Altschuler et al., 1986). To correlate the location of receptor proteins and the corresponding mRNAs, we examined double-labeled sections under confocal laser scanning microscopy. Fluorescent ISHs for GlyR complex mRNAs (red in Fig. 2) were performed together with immunofluorescent detection for the GlyR or gephyrin proteins (green in Fig. 2) to assess the subcellular localization of the GlyR complex mRNAs. Using a specific monoclonal antibody against $\alpha$ and $\beta$ subunits of GlyR (mAb 4a) (Pfeiffer et al., 1984), we demonstrated that GlyR $\alpha 1$ or $\alpha 2$ subunit mRNAs were expressed concomitantly with GlyRs in neuronal cell bodies and dendrites (Fig. 2A,B). Furthermore, GlyR $\alpha 1$ and $\alpha 2$ subunit mRNAs were unevenly distributed within the perikaryal and dendritic cytoplasm, and tended to form aggregates, in particular near dendritic branch points (Fig. 2A,B).

The extension of GlyR $\alpha 1$ and $\alpha 2$ subunit mRNAs within dendrites was not measured because many of the processes were cut off during the preparation of the specimen. Nevertheless, within the plane of the section it was possible to follow the hybridization signal over the entire dendritic length (Figs. $1 A, B, 2 A, B)$.

In contrast to the GlyR $\alpha 1$ and $\alpha 2$ subunits, superimposition of fluorescent ISH images with oligonucleotide probes for $\beta$ subunit and gephyrin with those for immunostaining for GlyR and gephyrin proteins from the same cell revealed that these mRNAs were predominantly localized within neuronal somata and around the nucleus (Fig. 2C,D). 


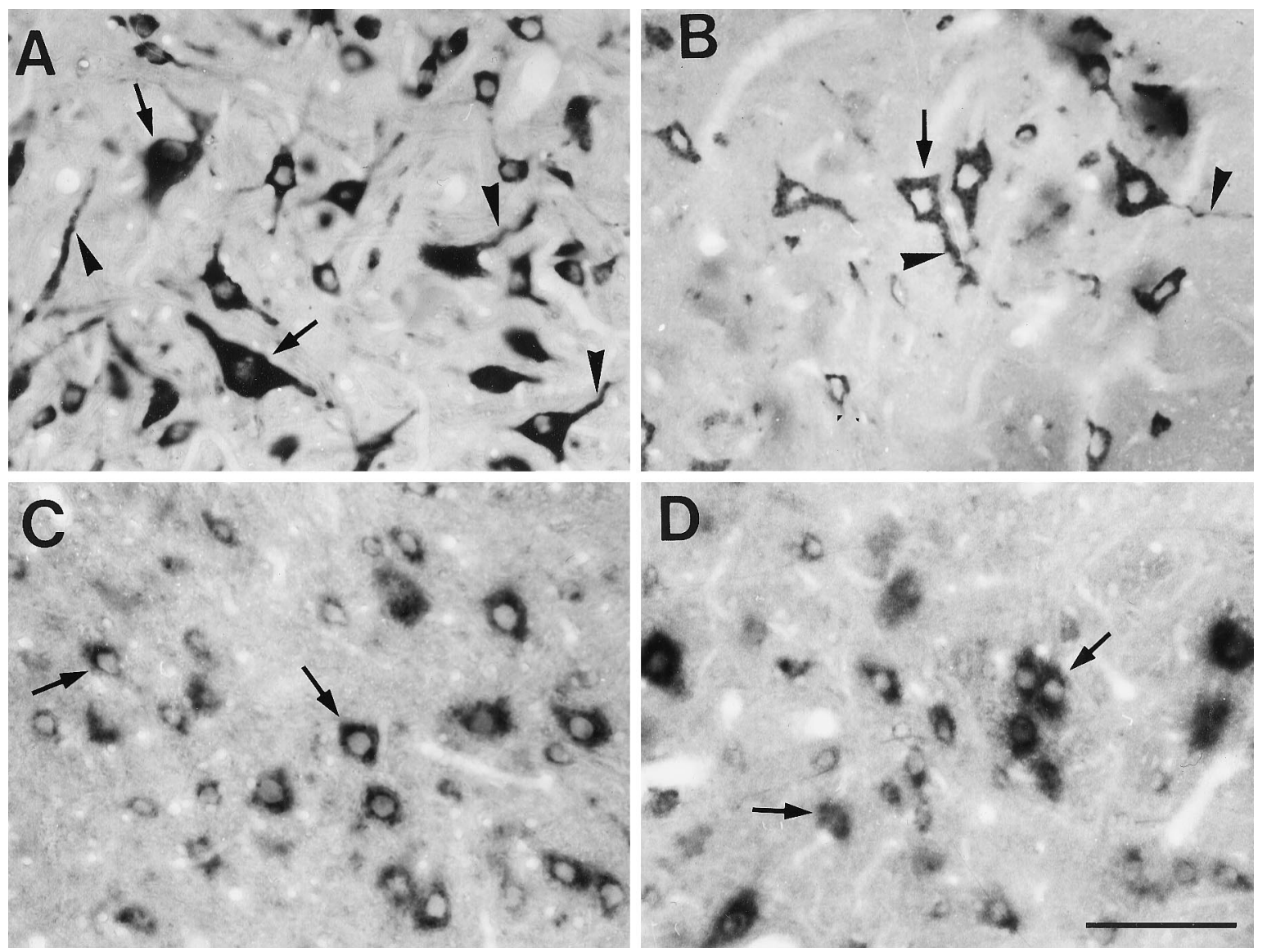

Figure 1. Localization of GlyR subunit and gephyrin mRNAs in ventral horn spinal cord neurons revealed by alkaline phosphatase enzymatic reaction product. Glycine receptor $\alpha 1(A)$ and $\alpha 2(B)$ mRNAs are detected in both somata (arrows) and neurites (arrowheads), whereas GlyR $\beta$ subunit $(C)$ and gephyrin $(D)$ mRNAs are predominantly in the cell bodies (arrows). All examples are from the same animal and experiment. Photos were processed identically. Scale bar, $100 \mu \mathrm{m}$.

\section{Subcellular localization of GlyR $\alpha$ subunit mRNAs}

The subcellular localization of GlyR $\alpha$ subunit mRNAs within neurons was investigated by preembedding DAB and immunogold EM ISHs. No differences in the subcellular distribution patterns were observed between GlyR $\alpha 1$ and $\alpha 2$ subunit mRNAs.

\section{Soma}

In the neuronal soma, the horseradish peroxidase (HRP) reaction product, corresponding to $\alpha 1$ subunit mRNA signal, was discontinuous in the cytoplasm, forming scattered aggregates, often associated with cisternae of the endoplasmic reticulum and accumulating at postsynaptic sites (Fig. $3 A$ ). The finding that these mRNAs were associated with cisternae of the reticulum and not with the Golgi complex was confirmed by gold labeling (Fig. 3B). Accumulations of gold particles were often observed in the cytoplasm between the stacks of the reticulum organized to form Nissl bodies (Fig. 3C,D). GlyR $\alpha 2$ subunit mRNAs showed the same distribution pattern (data not shown).

\section{Dendrites}

High-resolution confocal microscopy of double-labeling fluorescence experiments showed that within dendrites the hybridization signals for GlyR $\alpha$ subunit mRNAs were uneven. The confocal sections (Fig. $4 A, B$ ) revealed that the mRNAs for $\alpha 1$ subunit formed aggregates that tended to localize at the dendritic periph- ery close to the plasmalemma. The fluorescence associated with $\alpha 1$ subunit mRNAs, in many cases, colocalized with the GlyR immunoreactivity (Fig. 4A-C), as was also observed at lower resolution for GlyR $\alpha 1$ and $\alpha 2$ subunit mRNAs (Fig. 2A,B). Occasionally, the hybridization signal was all over the surface of the dendritic section (Fig. $4 C$ ).

We studied the fine localization of GlyR $\alpha$ subunit mRNAs in dendrites at the EM level with HRP or gold labeling. The enzymatic HRP reaction product corresponding to $\alpha 1$ subunit mRNAs (Fig. 4D) predominated along the dendritic plasmalemma and decorated the postsynaptic differentiations. Some of this staining may have resulted from diffusion of the HRP reaction product, and its subsequent adsorbtion on the dense subsynaptic cytoskeleton. However, as confirmed by gold labeling (see below), this staining indicated that the oxidizing enzyme was not far from the precipitated chromogen. Clusters of HRP labeling were also detected within the dendroplasma and may correspond to the aggregates of mRNA seen with confocal microscopy (Fig. $4 A-C$ ). The validity of the postsynaptic labeling was confirmed by gold ISH staining. Some gold particles were present at distances $<0.5 \mu \mathrm{m}$ from the postsynaptic differentiations (Fig. 4E).

When the HRP enzymatic reaction for EM ISH was weak, we could observe subsynaptic cisternae within the electron-dense 

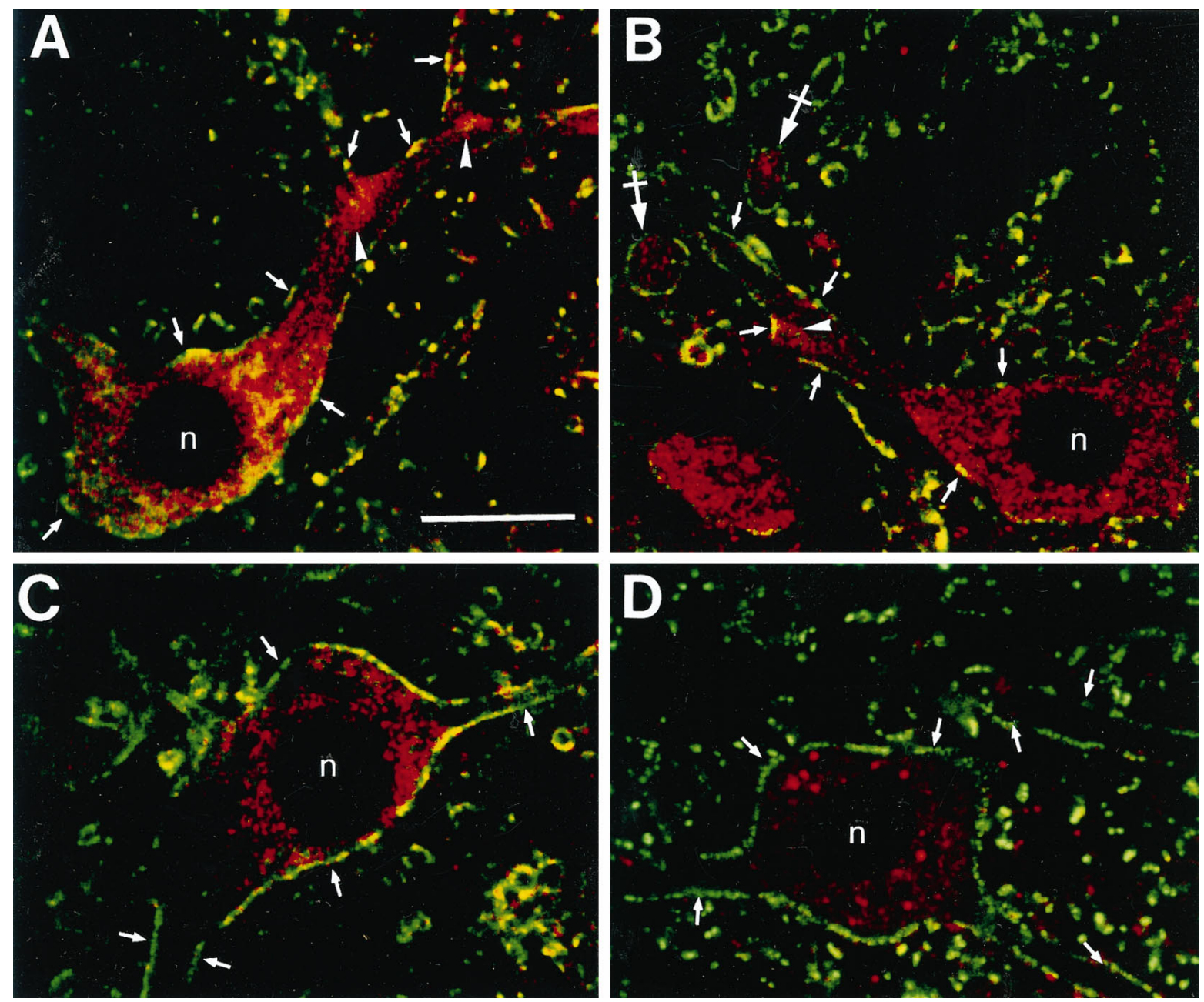

Figure 2. Double-fluorescence labeling of GlyR and gephyrin mRNAs and of the corresponding proteins detected with confocal microscopy. In each case, the mRNA signals are red, and the immunoreactivities for GlyR (mAb 4a) and gephyrin (mAB 7a) proteins are green. $A, B$, Presence of $\alpha 1(A)$ and $\alpha 2(B)$ mRNAs in somata and dendrites. Note their accumulation at dendritic branch points (arrowheads). Cross sections of dendrites $(B ;$ crossed arrows) containing $\alpha 2$ mRNAs. $C, D$, GlyR $\beta$ subunit $(C)$ and gephyrin $(D)$ mRNAs are predominantly in the somata. The mRNA signals are red, and the immunoreactivities for GlyR and gephyrin proteins are green. The postsynaptic GlyR $(A-C)$ and gephyrin $(D)$ immunoreactivities $($ arrows $)$ delineate neurons and dendrites. The nuclei $(n)$ are not stained. Pixel size, $0.2 \mu \mathrm{m}$. Scale bar, $25 \mu \mathrm{m}$.

product for the $\alpha 1$ subunit mRNA (Fig. $4 F$ ). Furthermore, the gold labeling showed that the GlyR $\alpha 1$ subunit mRNAs were often adjacent to these submembranous cisternae near synaptic contacts (Fig. 4G). Associations of gold particles with subsynaptic cisternae were repeatedly found (Fig. 5). A similar relationship was also observed for $\alpha 2$ subunit using both the HRP (Fig. 6A,B) and the gold (Fig. 6C,D) ISH detections of mRNAs.

\section{DISCUSSION}

\section{Uneven distribution of GlyR $\alpha$ subunit mRNAs and dendritic transport}

In ventral horn spinal cord neurons, we observed that the mRNAs for GlyR $\alpha 1$ and $\alpha 2$ subunits tended to form aggregates within somata and dendrites, which accumulated at dendritic branch points. Many mRNAs have been shown to form aggregates (Bruckenstein et al., 1990; Kleiman et al., 1990; Sundell and Singer, 1991; Ainger et al., 1993a,b; Ferrandon et al., 1994; Barbarese et al., 1995). Studies in various cell types indicate that cytoskeletal elements participate in mRNA movement and local- ization to the cell processes or compartments (Bruckenstein et al., 1990; Yisraeli et al., 1990; Sundell and Singer, 1991; Ainger et al., 1993a,b; Bassell et al., 1994; Ferrandon et al., 1994). Davis et al. (1987, 1990) have shown that newly synthesized mRNAs are actively transported in association with the cytoskeleton into the dendrites of hippocampal neurons. Thus, individual aggregates of GlyR $\alpha$ subunit mRNAs are likely to be the structural units for transport. In addition, these aggregates may include trans-acting factors involved in movement, targeting, stabilization of the mRNA itself, and protein synthesis (Barbarese et al., 1995; St Johnston, 1995).

The intracellular transport of mRNAs has been studied extensively in oligodendrocytes (Ainger et al., 1993a,b; Barbarese et al., 1995), where myelin basic protein (MBP) mRNAs form granules together with molecular components of the protein synthetic machinery. Granules move with continuous motion down the oligodendrocyte processes and at branch points tend to oscillate, possibly forming clusters with other granules (Ainger et al., 1993a,b). It has been postulated that clustering of granules at branch points reflect a sorting mechanism to direct MBP mRNA 

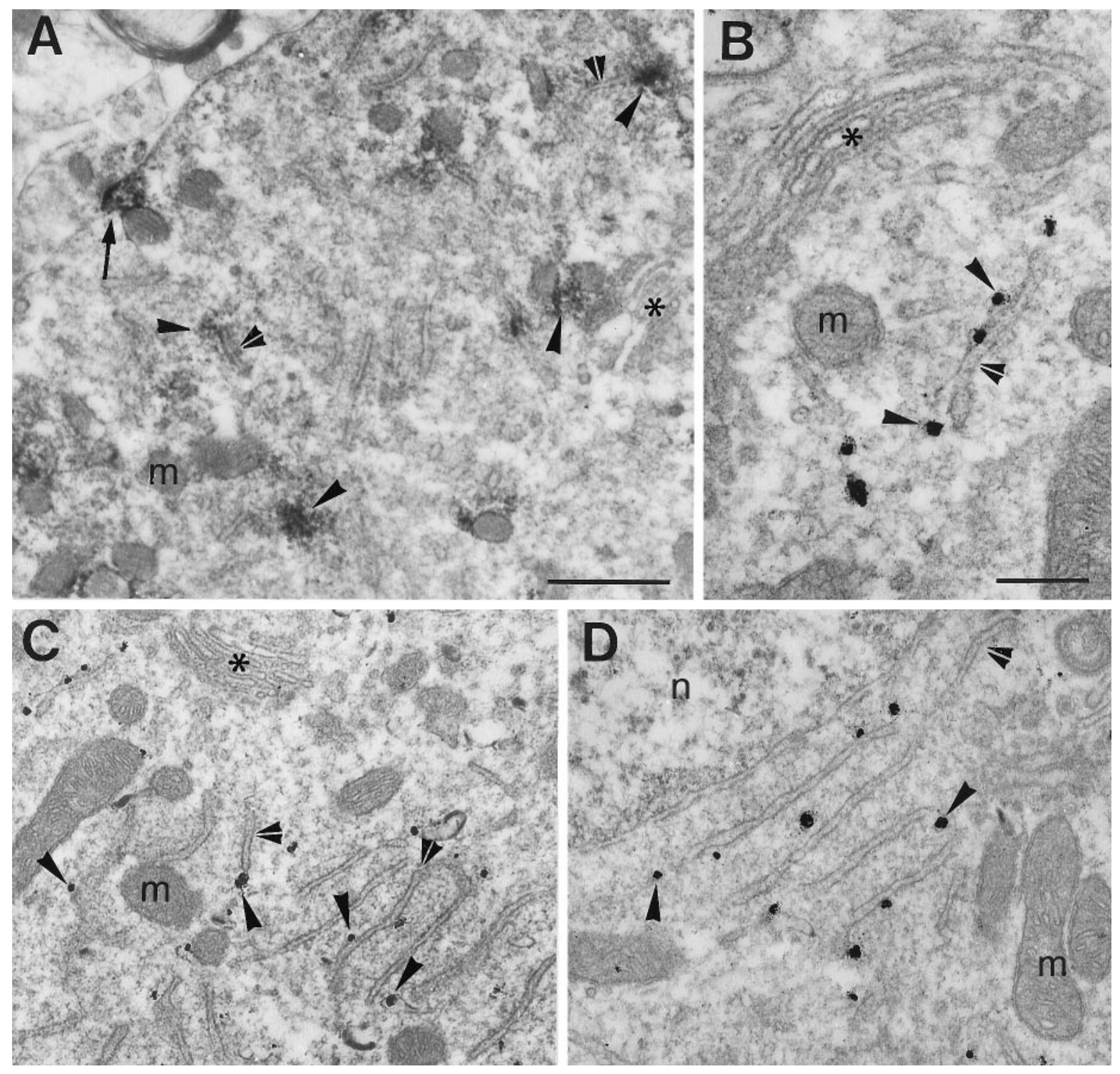

Figure 3. Subcellular localization of GlyR $\alpha 1$ subunit mRNAs in the somata of central horn neurons. $A$, Uneven distribution of transcripts visualized with HRP reaction product (arrowheads), which is frequently associated with cisternae (double arrowheads). Presence of an electron-dense HRP reaction product in front of a synaptic contact (arrow). B, Gold particles (arrowheads) associated with the mRNA are adjacent to a cisterna (double arrowhead). $C$, Lower magnification from the same neuron as in $B . D$, Further example showing the close relationship of the gold particles with cisternae of the Nissl bodies. Note that in $A-C$ the Golgi apparatus (asterisks) are not decorated with either HRP reaction product or gold particles, respectively. $m$, Mithocondrium; $n$, nucleus. Scale bars: $A, C, 0.5 \mu \mathrm{m} ; B, D, 0.25 \mu \mathrm{m}$.

transport to particular branch processes. In addition, it could function to direct myelin formation in vivo around particular axons (Ainger et al., 1993a,b). Similarly, the accumulation of GlyR $\alpha 1$ or $\alpha 2$ mRNA aggregates at dendritic branch points might result from a mechanism comparable to that observed in oligodendrocytes. It is possible, therefore, that the GlyR $\alpha$ subunit mRNAs can be directed, by an active process, to preferentially enter one or the other dendritic branch.

\section{Postsynaptic localization of GlyR $\alpha$ subunit mRNAs and protein synthetic machinery}

Following the initial work of Bodian (1965), most of the elements of the protein synthetic machinery have been found beneath synaptic sites, not only at the soma but also in dendrites (Steward and Reeves, 1988). Moreover, it has been shown that protein synthesis occurs at the postsynaptic dendritic membrane (Rao and Steward, 1991; Torre and Steward, 1992).

Double detection with confocal microscopy revealed that GlyR $\alpha 1$ or $\alpha 2$ mRNAs and GlyR were frequently colocalized. Within the spinal cord, GlyR-positive postsynaptic differentiations are apposed to terminal boutons that contain glycine (Todd et al., 1996). In most cases, the mRNAs were in front of endings containing a pleomorphic population of vesicles, an ultrastructural feature often associated with inhibitory function (see references in Peters et al., 1991). Therefore, GlyR $\alpha$ mRNAs are likely to be localized in front of glycinergic synaptic contacts. As seen with EM, the GlyR $\alpha$ subunit mRNAs were associated with cisternae underneath dendritic synapses. This association raises the question of whether these membrane-limited elements are involved in 

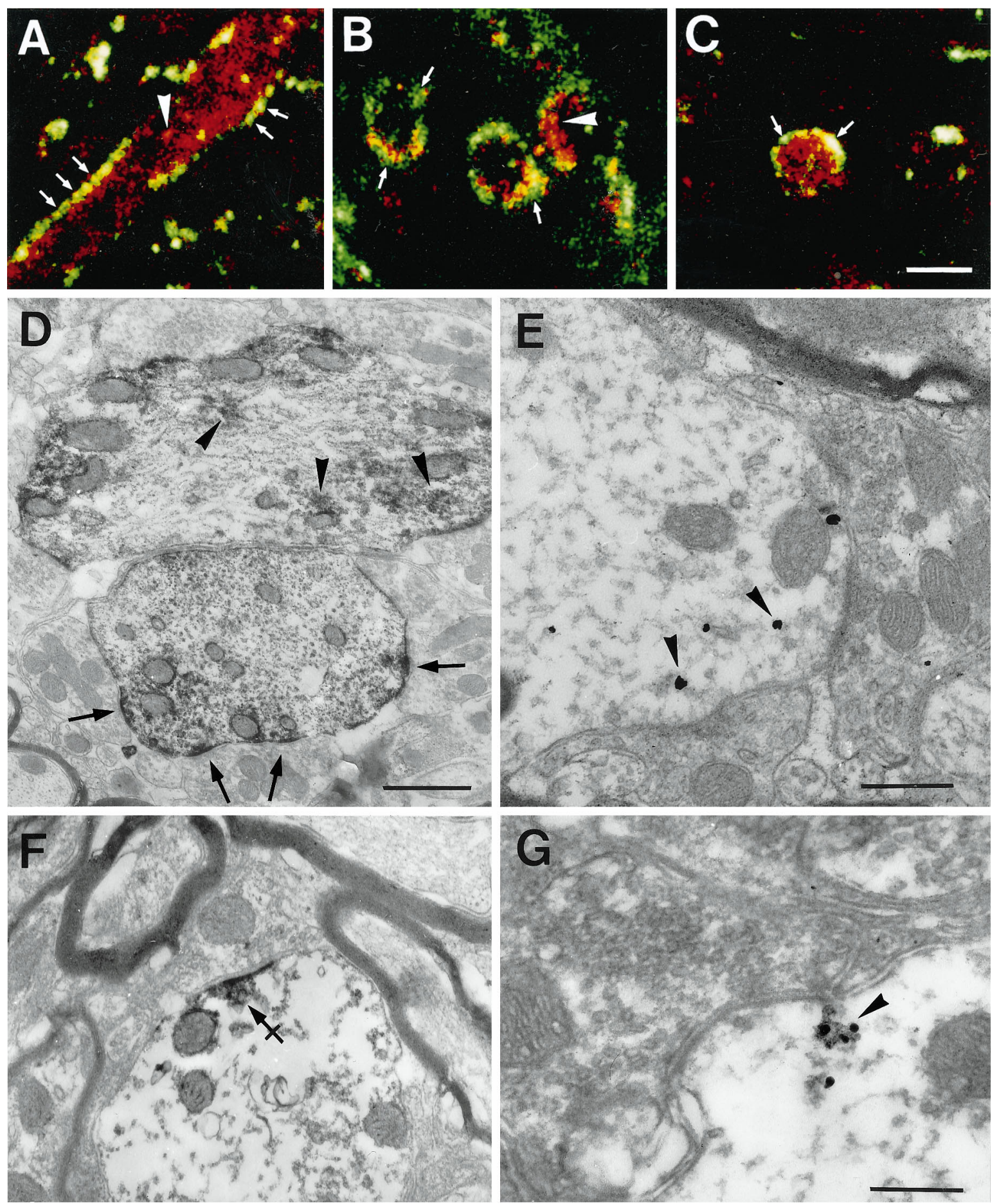

Figure 4. Dendritic and subsynaptic localization of GlyR $\alpha 1$ subunit mRNAs. $A-C$, Examples of optical sections of dendrites obtained with a confocal microscope (pixel size, $0.1 \mu \mathrm{m}$ ). In most cases, the mRNAs (red) were predominantly at the neurite periphery, here outlined by GlyR immunoreactivity ( green; arrows), as seen on longitudinal $(A)$ or transversal $(B)$ views. Note that the mRNAs tend to form aggregates (arrowheads) within dendrites. In some dendrites $(C)$, the mRNAs appear evenly distributed throughout the dendritic cross section. Colocalization of mRNA signal with GlyR immunoreactivity ( yellow; $A-C$ ). D, EM ISH of mRNAs visualized in dendrites by HRP reaction product showing their tendency to accumulate peripherally to the dendritic center, and in front of synapses (arrows). Within dendrites, the mRNA signal is discontinuous and forms aggregates (arrowheads). E, The mRNAs detected by gold labeling (arrowheads) at the dendritic periphery are next to synapses. $F$, Decoration of the postsynaptic density by the HRP enzymatic reaction product. Note the presence of small subsynaptic cisternae (crossed arrow). G. Presence of gold-labeled mRNAs (arrowhead) on a minute cisterna, postsynaptic to a bouton containing pleomorphic vesicles. Scale bars: $A-C, 5 \mu \mathrm{m} ; D, 1 \mu \mathrm{m} ; E, F, 0.5 \mu \mathrm{m} ; G, 0.25 \mu \mathrm{m}$. 

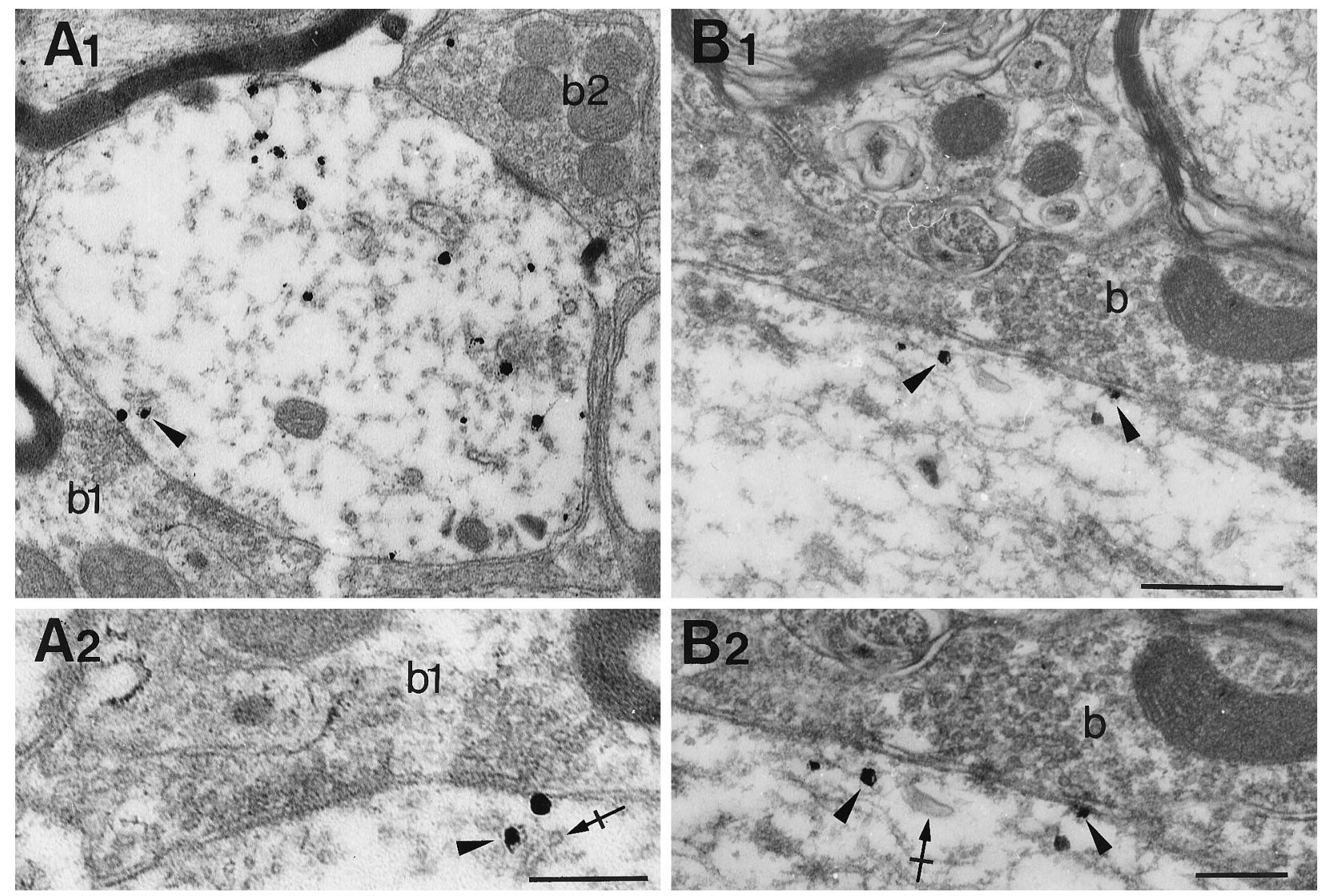

Figure 5. Gold particles associated to GlyR $\alpha 1$ subunit mRNA (arrowheads) are close to subsynaptic cisternae (crossed arrows). Examples at low-power $(A 1, B 1)$ and high-power $(A 2, B 2)$ magnifications, respectively. $A 2$, Terminal bouton with pleomorphic vesicles $(b)$. $b$, Terminal bouton. Scale bars: $A 1$, $B 1,0.5 \mu \mathrm{m} ; A 2, B 2,0.25 \mu \mathrm{m}$.

local protein synthesis. In rat spinal cord neurons, the submembranous cisternae, lying beneath synapses and the dendritic plasma membrane, are continuous with components of both the smooth and the rough endoplasmic reticulum (Rosenbluth, 1962; Peters et al., 1991). Morphologically, these cisternae differ in configuration from the ones of a typical Golgi complex and appear to belong to the endoplasmic reticulum network (Rosenbluth, 1962). In our study, we could not reliably detect ribosomes associated with these cisternae, possibly because of the overnight hybridization at $42^{\circ} \mathrm{C}$ before osmification. Even at the level of the Nissl bodies, which are rich in ribosomes (Peters et al., 1991), ribosomes could not be unequivocally detected (see Fig. 3C,D). Alternatively, the ribosome density at subsynaptic cisternae could be very low. Nonetheless, the rough endoplasmic reticulum is present in dendrites of ventral horn spinal cord neurons (Peters et al., 1991).

The $\alpha$ subunits of the GlyR are glycosylated proteins (Hoch et al., 1989). Recently, Torre and Steward (1996) have shown that glycosylation takes place in the dendrites of hippocampal neurons in culture. Furthermore, we have found in spinal cord neurons of the ventral horn (A. Triller and A. Gardiol, unpublished observations) that flat continuous cisternae, parallel to the dendritic plasma membrane, are immunoreactive for an antibody recognizing a protein that resides in the cis-Golgi network apparatus and that may cycle between the Golgi apparatus and the intermediate compartment (p210 Ab) (Rios et al., 1994). Together, these findings support the notion that dendrites, as compartments for macromolecular synthesis (Steward, 1994), can perform some of the post-translational modifications normally occurring in the endoplasmic reticulum and Golgi apparatus.

\section{Functional implications of dendritic and subsynaptic localizations of GlyR $\alpha$ subunit mRNAs}

During development, native GlyRs show different electrophysiological and pharmacological properties that are probably attributable to diversities in the subunit composition. Recombinant GlyR subunits have been shown to assemble functional heteroand homomeric channels in in vitro expression systems. Such recombinant channels differ in their physiology and pharmacology depending on the subunit composition, and their physiological properties are similar to those of native receptors (Kirsch and Betz, 1995). Thus, the functional diversity of native GlyR may result in part from the expression of various combination of GlyR mRNAs. There are two ways for newly synthesized GlyR $\alpha$ subunits close to postsynaptic sites to alter the postsynaptic response: (1) changes in receptor subunit composition result in GlyRs with different physiological properties, and (2) new GlyRs might change the size of the response. Such mechanisms might explain some of the observed changes during development and synaptic plasticity.

In adult neurons, the location of translation of a specific protein may control the local response to external stimuli or environmental changes and could participate in fine functional regulation at the site 

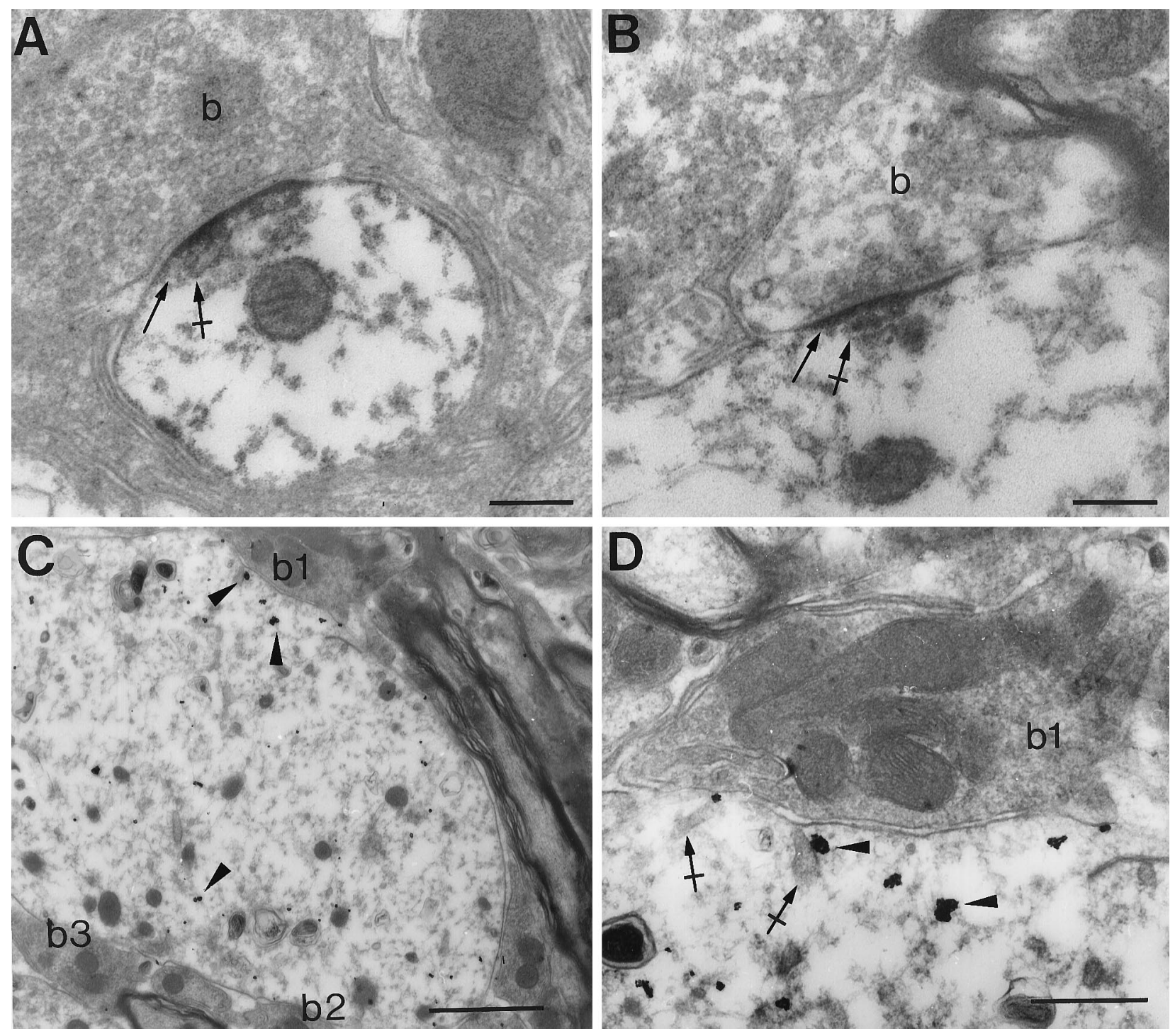

Figure 6. Dendritic and subsynaptic localizations of GlyR $\alpha 2$ subunit mRNA. $A, B$, HRP reaction product (arrows) at postsynaptic densities and associated with submembranous cisternae (crossed arrows). $C, D$, Presence of gold particles (arrowheads) within a dendrite and beneath a terminal bouton (b1). Gold particles can be associated with cisternae (crossed arrows). $b$, Terminal bouton. Scale bars: $A, B, 0.2 \mu \mathrm{m} ; C, 1 \mu \mathrm{m} ; D, 0.5 \mu \mathrm{m}$.

of the local stimulus (Thomas et al., 1994; Link et al., 1995; Lyford et al., 1995). The presence of GlyR $\alpha$ subunit mRNAs close to postsynaptic differentiations provides neurons with a ready-to-use pool of specific mRNAs that may be translated in the corresponding proteins in situ (Steward and Levy, 1982; Steward, 1983; Steward and Fass, 1983; Steward and Reeves, 1988; Hoch et al., 1989; Peters et al., 1991; Torre and Steward, 1992).

Evidence for a long-term potentiation of glycinergic transmission induced by VIII nerve tetanic stimulations was obtained in the Goldfish Mauthner cells (Charpier et al., 1995). After stimulation, previously silent or absent GlyRs become functional, thus contributing to the potentiation of the inhibitory synapses. As proposed for glutamatergic transmission (Isaac et al., 1995; Liao et al., 1995), "uncovering” of GlyRs could underlie changes in synaptic efficacy. An alternative hypothesis is that receptors are synthesized in close proximity and subsequently inserted into the postsynaptic membrane. It has been shown in heterologous expression systems that homo- meric GlyRs are functional (Bormann et al., 1993). Therefore, targeting of $\alpha$ subunit transcripts to dendritic compartments may imply that hetero- and homomeric GlyRs have different roles in neuronal function (for instance, the homomeric GlyRs might be involved in plasticity). Indeed, homomeric receptors can be synthesized by neurons as shown in spinal cord primary cultures (Hoch et al., 1989).

The half-lives of homomeric $\alpha$ or heteromeric $\alpha 1 / \alpha 2$ GlyRs compared to heteromeric $\alpha / \beta$ GlyRs at dendritic synapses remain unclear (Hoch et al., 1989). The GlyR $\beta$ subunit binds to gephyrin (Meyer et al., 1995), and gephyrin is associated with microtubules (Kirsch and Betz, 1995). Therefore, the heteromeric $\alpha / \beta$ GlyR is likely to have a longer lifespan in the membrane because of its stabilization by the cytoskeleton. If there is a difference in turnover, the GlyR $\alpha$ subunit mRNAs in dendrites could have an additional function. Dendritic mRNAs might provide a transcript source for local synthesis of new $\alpha$ subunits that could then rapidly assemble to form the homo- or heteromeric $\alpha 1 / \alpha 2$ receptors. 


\section{REFERENCES}

Ainger K, Avossa D, Morgan F, Hill SJ, Barry C, Barbarese E, Carson JH (1993a) Transport and localization of exogenous myelin basic protein mRNA microinjected into oligodendrocytes. J Cell Biol 123:431-441.

Ainger K, Hill S, Smith CL, Hill SJ, Barbarese E, Carson JH (1993b) Transport and localization of MBP mRNA within multicomponent granules in oligodendrocytes. Mol Biol Cell [Suppl] 4:421a.

Altschuler RA, Betz H, Parakkal M, Reeks K, Wenthold R (1986) Identification of glycinergic synapses in the cochlear nucleus through immunocytochemical localization of the postsynaptic receptor. Brain Res 369:316-320.

Barbarese E, Koppel DE, Deutscher MP, Smith CL, Ainger K, Morgan F, Carson J (1995) Protein translation components are colocalized in granules in oligodendrocytes. J Cell Sci 108:2781-2790.

Bassell GJ, Singer RH, Kosik KS (1994) Association of poly(A) mRNA with microtubules in cultured neurons. Neuron 12:571-582.

Bodian D (1965) A suggestive relationship of nerve cell RNA with specific synaptic sites. Proc Natl Acad Sci USA 53:418-425.

Bormann J, Rundström N, Betz H, Langosh D (1993) Residues within transmembrane segment M2 determine chloride conductance of glycine receptor homo- and hetero-oligomers. EMBO J 12:3729-3737.

Bruckenstein DA, Lein PJ, Higgins D, Fremeau Jr RT (1990) Distinct spatial localization of specific mRNAs in cultured sympathetic neurons. Neuron 5:809-819.

Charpier S, Behrends JC, Triller A, Faber DS, Korn H (1995) Latent inhibitory connections become functional during activity-dependent plasticity. Proc Natl Acad Sci USA 92:117-120.

Davis L, Banker GA, Steward O (1987) Selective dendritic transport of RNA in hippocampal neurons in culture. Nature 330:477-479.

Davis L, Burger B, Banker GA, Steward O (1990) Dendritic transport: quantitative analysis of the time course of somatodendritic transport of recently synthesized RNA. J Neurosci 10:3056-3068.

Dotti CG, Simons K (1990) Polarized sorting of viral glycoproteins to the axons and dendrites of hippocampal neurons in culture. Cell 62:63-72.

Ferrandon D, Elphick L, Nüsslein-Volhard C, St Johnston D (1994) Staufen protein associates with the $3^{\prime}$ UTR of bicoid mRNA to form particles that move in a microtubule-dependent manner. Cell 79:1221-1232.

Grenningloh G, Rienitz A, Schmitt B, Methfessel C, Zensen M, Beyreuther K, Gundelfinger ED, Betz H (1987) The strychninebinding subunit of the glycine receptor shows homology with nicotinin acetylcholine receptors. Nature 328:215-220.

Grenningloh G, Pribilla I, Prior P, Multhaup G, Beyreuther K, Taleb O, Betz $\mathrm{H}$ (1990) Cloning and expression of the $58 \mathrm{kd} \beta$ subunit of the inhibitory glycine receptor. Neuron 4:963-970.

Hoch W, Betz H, Becker C-M (1989) Primary cultures of mouse spinal cord express the neonatal isoform of the inhibitory glycine receptor. Neuron 3:339-348.

Isaac JTR, Nicoll RA, Malenka C (1995) Evidence for silent synapses: implications for the expression of LTP. Neuron 15:427-434.

Kirsch J, Betz H (1995) The postsynaptic localization of the glycine receptor-associated protein gephyrin is regulated by the cytoskeleton. J Neurosci 15:4148-4156.

Kirsch J, Langosh D, Prior P, Littauer UZ, Schmitt B, Betz H (1991) The $93 \mathrm{kDa}$ glycine receptor-associated protein binds to tubulin. J Bio Chem 266:22242-22245.

Kirsch J, Malosio M-L, Wolters I, Betz H (1993a) Distribution of gephyrin transcripts in the adult and developing rat brain. Eur $\mathbf{J}$ Neurosci 5:1109-1117.

Kirsch J, Wolters I, Triller A, Betz H (1993b) Gephyrin antisense oligonucleotides prevent glycine receptor clustering in spinal neurons. Nature 366:745-748.

Kleiman R, Banker G, Steward O (1990) Differential subcellular localization of particular mRNAs in hippocampal neurons in culture. Neuron 5:821-830.

Kuhse J, Schmieden V, Betz H (1990) A single amino acid exchange alters the pharmacology of neonatal rat glycine receptor subunit. Neuron 5:867-873.

Kuhse J, Betz H, Kirsch J (1995) The inhibitory glycine receptor: architecture, synaptic localization and molecular pathology of a postsynaptic ion-channel complex. Curr Opin Neurobiol 5:318-323.

Langosch D, Thomas L, Betz H (1988) Conserved quaternary structure of ligand-gated ion channels: the postsynaptic glycine receptor is a pentamer. Proc Natl Acad Sci USA 85:7394-7398.

Liao D, Hessler NA, Malinow R (1995) Activation of postsynaptically silent synapses during pairing-induced LTP in CA1 region of hippocampal slice. Nature 375:400-404.

Link W, Konietzko U, Kauselmann G, Krug M, Schwanke B, Frey U, Kuhl D (1995) Somatodendritic expression of an immediate early gene is regulated by synaptic activity. Proc Natl Acad Sci USA 92:5734-5738.

Lyford GL, Yamagata K, Kaufmann WE, Barnes CS, Sanders LK, Copeland NG, Gilbert DJ, Jenkins NA, Lanahan AA, Worley PF (1995) Arc, a growth factor and activity-regulated gene, encodes a novel cytoskeleton-associated protein that is enriched in neuronal dendrites. Neuron 14:433-445.

Malosio M-L, Marquèze-Pouey B, Kuhse J, Betz H (1991) Widespread expression of glycine receptor subunit mRNAs in the adult and developing rat brain. EMBO J 9:2401-2409.

Meyer G, Kirsch J, Betz H, Langosch D (1995) Identification of a gephyrin binding motif on the glycine receptor $\beta$ subunit. Neuron 15:563-572.

Pelhalm HRB, Munro S (1993) Sorting of membrane proteins in the secretory pathway. Cell 75:603-605.

Peters A, Palay SL, Webster H de F (1991) The fine structure of the nervous system. Oxford: Oxford UP.

Pfeiffer F, Simler R, Grenningloh G, Betz H (1984) Monoclonal antibodies and peptide mapping reveal structural similarities between the subunits of the glycine receptor of rat spinal cord. Proc Natl Acad Sci USA 81:7224-7227.

Prior P, Schmitt B, Grenningloh G, Pribilla I, Multhaup G, Beyreuther K, Maulet Y, Werner P, Langosch D, Betz H (1992) Primary structure and alternative splice variants of gephyrin, a putative glycine receptortubulin linker protein. Neuron 8:1161-1170.

Racca C, Gardiol A, Triller A (1996) Glycine receptor $\alpha$ subunit mRNAs in dendrites of rat spinal cord neurones. Soc Neurosci Abstr 22:784.

Rao A, Steward O (1991) Evidence that protein constituents of postsynaptic membrane specializations are locally synthesized: analysis of proteins synthesized within synaptosomes. J Neurosci 11:2881-2895.

Rindler MJ, Ivanov IE, Pleken H, Rodriguez-Boulan E, Sabatini D (1984) Viral glycoproteins destined for apical or basolateral plasma membrane domains traverse the same Golgi apparatus during their intracellular transport in doubly infected Madin-Darby canine kidney cells. J Cell Biol 98:1304-1319.

Rios RM, Tassin AM, Celati C, Antony C, Boissier MC, Homberg JC, Bornens M (1994) A peripheral protein associated with the cis-Golgi network redistributes in the intermediate compartment upon brefeldin A treatment. J Cell Biol 125:997-1013.

Rosenbluth J (1962) Subsurface cisterns and their relationship to the neuronal plasma membrane. J Cell Biol 13:405-421.

Sato K, Zhang J-T, Saika T, Sato M, Tada K, Tohyama M (1991) Localization of glycine receptor $\alpha 1$ subunit mRNA-containing neurons in the rat brain: an analysis using in situ hybridization histochemistry. Neuroscience 43:381-395.

Seitanidou T, Triller A, Korn H (1988) Distribution of glycine receptors on the membrane of a central neuron: an immunoelectron microscopy study. J Neurosci 8:4319-4333.

Steward O (1983) Polyribosomes at the base of dendritic spines of CNS neurons: their possible role in synapse construction and modification. Cold Spring Harb Symp Quant Biol 48:745-759.

Steward O (1994) Dendrites as compartments for macromolecular synthesis. Proc Natl Acad Sci USA 91:10766-10768.

Steward O (1995) Targeting of mRNAs to subsynaptic microdomains in dendrites. Curr Opin Neurobiol 5:55-61.

Steward O, Falk PM (1985) Polyribosomes under developing spine synapses: growth specializations of dendrites at sites of synaptogenesis. J Neurosci Res 13:75-88.

Steward O, Fass B (1983) Polyribosomes associated with dendritic spines in the denervated dentate gyrus: evidence for local regulation of protein synthesis during reinnervation. Prog Brain Res 58:131-136.

Steward O, Levy WB (1982) Preferential localization of polyribosomes under the base of dendritic spines in granule cells of the dentate gyrus. J Neurosci 2:284-291.

Steward O, Reeves TM (1988) Protein-synthetic machinery beneath postsynaptic sites on CNS neurons: association between polyribosomes and other organelles at the synaptic site. J Neurosci 8:176-184.

St Johnston D (1995) The intracellular localization of messenger RNAs. Cell 81:161-170.

Sundell CL, Singer RH (1991) Requirement of microfilaments in sorting of actin mRNAs. Science 253:1275-1277.

Thomas KL, Laroche S, Errington ML, Bliss TVP, Hunt SP (1994) 
Spatial and temporal changes in signal transduction pathways during LTP. Neuron 13:737-745.

Todd AJ, Watt C, Spike RC, Sieghart W (1996) Colocalization of GABA, glycine, and their receptors at synapses in the rat spinal cord. J Neurosci 16:974-982.

Torre ER, Steward O (1992) Demonstration of local protein synthesis within dendrites using a new cell culture system that permits the isolation of living axons and dendrites from their cell bodies. J Neurosci 12:762-772.

Torre ER, Steward O (1996) Protein synthesis within dendrites: glycosylation of newly synthesized proteins in dendrites of hippocampal neurons in culture. J Neurosci 16:5967-5978.

Trembleau A, Morales M, Bloom FE (1994) Aggregation of vasopressin mRNA in subset of axonal swellings of the median eminence and posterior pituitary: light and electron microscopic evidence. J Neurosci 14:39-53.

Triller A, Cluzeaud F, Pfeiffer F, Betz H, Korn H (1985) Distribution of glycine receptors at central synapses: an immunoelectron microscopy study. J Cell Biol 101:683-688.

Triller A, Cluzeaud F, Korn H (1987) Gamma-aminobutyric acidcontaining terminals can be apposed to glycine receptors at central synapses. J Cell Biol 104:947-956.

van den Pol AN, Gorcs T (1988) Glycine and glycine receptor immunoreactivity in brain and spinal cord. J Neurosci 8:472-492.

Yisraeli JK, Sokol S, Melton DA (1990) A two-step model for the localization of maternal mRNA in Xenopus oocytes: involvement of microtubules and microfilaments in the translocation and anchoring of $\mathrm{Vg} 1$ mRNA. Development 108:289-298. 